\title{
Taiwan's Chinese Language Development and the Creation of Language Teaching Analysis
}

\author{
Cheng-Hui Tsai ${ }^{1, *}$,Chuan-Po Wang ${ }^{2}$ \\ ${ }^{1}$ Department of Chinese Literature, National Taiwan University, Taiwan \\ ${ }^{2}$ Department of Industrial Design, National Cheng Kung University, Taiwan
}

Copyright (C) 2015 Horizon Research Publishing All rights reserved.

\begin{abstract}
Chinese Teaching in Taiwan in recent years in response to the international trend of development, making at all levels of Chinese language teaching in full swing, for the recent boom in Chinese language teaching, many overseas Chinese language learning for children also had a passion while actively learning Chinese language, and even many overseas ethnic Chinese children to learn Chinese language and went oceans, arrived in Taiwan to learn Mandarin. This study presents the Chinese language teaching, the definition is as "Chinese" as the Chinese language and voice, and "Chinese" is for the Chinese literature and culture; therefore will combine "cultural points" "language spots"; coherent development into a "Chinese Language Line "; then woven into a" Chinese language teaching face "; Finally, integration into the world," Chinese language curriculum integration network. " The integration of language teaching in China, among other disciplines, is very important for Chinese language teaching essence. Research will examine the views discussed "Chinese language integration courses" to carry out, how to make a solid foundation for Chinese language teaching language skills, you can make the Chinese language teaching to deepen the connotation of Chinese literature, culture, society, history ...... so, even indigenous multi-ethnic ...... and other related courses, either in Taiwan or overseas Chinese language teaching of foreign learners begin to experience the multicultural make baptism as the goal, and then deep essence and mystery of Chinese culture for thousands of years at the world, creating new culture of "diversity of thinking," and a full range of "polygonal learning" to make "cultural communities" international exchanges bring out the bright spark of a new era.
\end{abstract}

Keywords Chinese Language Curriculum Integration, Multiculturalism, Pluralism Thinking, Polygonal Learning, Ethnic Culture

\section{Introduction}

Chinese Teaching in Taiwan in recent years in response to the international trend of development, making at all levels of Chinese language teaching in full swing, "Chinese teaching Chinese teaching has always been not originally to life language teaching, emphasizing academic theory, but will focus attention on teaching and learning practices. "(Zhu Jinghua, 2006) Therefore, in addition to its core issues of Chinese language teaching materials compiled, teaching tests, language teaching theory and application, curriculum design application, psycholinguistics and language acquisition, overseas markets, corpus and language teaching, computer and Internet instruction, reading and writing, listening and speaking ...... and other aspects have yet diversified and all-round development, but the integration between the Chinese language teaching and other school door, by "Chinese language curriculum integration network" bring out the learners 'radioactive thinking "(Sun Yi Xin, 2002.10), as Albert Einstein once said:" imagination is more important than knowledge ", and to cultivate learners' active learning ',' win-win thinking "," Zhibi solution has "," integration synergies "," constantly updated "...... and so on high-performance learning habits (' Sean Covey Sean Covey), is the essence of Chinese language teaching is very important.

For the development trend of the global Chinese language teaching, in terms of the digital era "information explosion" is required to construct the future trend will be faced with "Chinese language integration courses" to carry out diversification, "Chinese language teaching is both art and science. the most important;. it is a separate discipline, is both refined and exclusive knowledge we have a responsibility to make Chinese teaching excellence and not biased in the right direction "(Zhao Zhichao, 2005) due to the very different Chinese language teaching in other subjects unique place, that is for its "cross-cultural subjects" perspectives in teaching history is bound to face broad and deep in other disciplines. Therefore, I will propose the Chinese language teaching, the definition is as "Chinese" as the Chinese language and voice, and "Chinese" is for the Chinese Literature and Culture, "from the point of view of teaching, teaching Chinese language really can not deviate from cultural factors regardless, however, over the years, 
many experts put forward various theories about the Chinese language teaching and insights from different angles at different levels, ...... on the whole, Chinese culture and Chinese language teaching in interactive question raised on the less. "(Wang Yongbing, 1995) so the new perspective by the author in this study Chinese language teaching, the proposed "language point" binding "cultural points"; coherent development into a "Chinese Language line"; then woven into a "Chinese language teaching face"; finally integration into the world, "Chinese language curriculum integration network." Therefore, Chinese language teaching will eventually build a new culture of "diversity of thinking," and a full range of "polygonal Learning ', so that the international" ethnic culture "has a diverse mix of opportunity.

The recent boom in Chinese language teaching, many overseas Chinese language learning for children also had a passion while actively learning Chinese language, and even many Chinese children lived in overseas for Chinese language learning to arrive in Taiwan, "Chinese is a just the emotional and cultural needs of the language, it is a clear understanding of their own national identity and self-esteem of the basic tools." (Lee Kuan Yew, 1990) However, cross-cultural study of overseas Chinese children across time and space generated overseas, but it cultural barriers arising due to temporal and spatial distance leaving the frustration felt. (Zhou Ping, 1994.12.27-30) Therefore, this Chinese language teaching "cross-cultural issues" has become an important topic of discussion, "a problem nowadays as a Foreign Language teachers often talk about is how to integrate language and culture." (Zhou Zhiping , 2005) Taiwan and China in the eighties trend affecting language "Oriental hot" in the international community, has attracted scholarly attention. "In recent years, many language teachers and academics are keen to discuss the issue of language teaching and culture combines teaching, this paper, on the Chinese language teaching profession, at least in the early 1980s there have been." (Bi Following Wan , Zhang Dexin, 1994) in recent years, the concept of globalization, global village, making Chinese language teaching, learning trend is sweeping the West.

Since the twentieth century's most distinguished cultural critic last years scholars, international political observers, and post-colonial thought opener, "Edward said," (Edward, Edward said Edward W.Said) in "Orientalism" in the "post-colonial" discussion, and Gramsci's "cultural hegemony theory", and Foo Ko's "knowledge power theory" under the "Orientalism in the East" among the disadvantages of being colonial. Modern global boom in Chinese "East Wind", has been quite different from the stereotype Edward said in a post-colonial theory of "Orientalism" in his book, mentioned "Oriental East" generated. This one from "Edward said German-style Orientalism" which evolved with the changing times, "New Orientalism", will help to improve the Chinese language teaching mushroomed thriving development. "Chinese students learning through inter imperceptibly, unconsciously, in terms of ideology will be inspired to conduct themselves in society, gradually training objectives of moral education." (Lin Xu Xing, 1988.12) global blowing an "East Wind "boom, and Chinese language teaching, is as one of the two sides complement each other," foreign learners in the learning of foreign language, language knowledge and cultural knowledge should be the same important.. "(Huang Miriam, 1996) in other words, namely" learning a second language and a second culture must keep pace. "(Lin Yihua, 2005) Edward said in" Orientalism ", the once said," conscious humanism, "the most important thing is the human" individual actions "and" body "Chinese language teaching in relation to itself, namely the West in the eyes of new Oriental, and Oriental, the Global Chinese world, by individual action symbolizes the new trend of the evolution of body conscious, bilingual teaching Chinese language which was proposed in this paper and Multiculturalism the new trend.

\section{The Bilingual Teaching}

For Chinese language teaching "bilingual education", the most important aspect is the "cross-language teaching", "important concepts of teaching vocabulary: words and culture have an important relationship, culture is often displayed in the language." (Zhu Jinghua, 2006) how to cross language vocabulary teaching process, through the translation conveys "thinking distance"? "Generally speaking, in the same language as the mother tongue of the nation must have the same culture when different ethnic relations, apart from the language differences make them feel very troubled, the cultural differences even more headaches." (Huang instrument, 1996) related topics This is called "cross-cultural communication" (Zhang accounted for one, 1996.1) produced, so how authentic presentation bilingual spans "cultural divide", making teaching across "languages era, cultural differences on the region. "and truthfully only be interpreted as true? "The relationship between culture and second language teaching, in recent years there has been many linguists working on this aspect." (Bu Ai Ying, 1995) because the language is anytime, anywhere, ever-changing transformation, such as the founder of modern linguistics Saussure said:

Whenever language is everybody's business, it is popular among the general public, for the public use, all the people all day using it, ...... "language" is both a function of the social product of speech, but also a social group for there may be a set of individuals to exercise this essential function used in the statute. (Chen Yuan, 1985)

And change across ethnic groups due to "cultural language" covered, it is treacherous and changeable, unpredictable, and values "since its ethnic community languages are closely related, of course, and ethnic politics, economy, culture, education, customs are closely linked and influence each other "(Ye Deming, 1996) views held by the author in this article, are based on culture as" spirit of the deep Chinese language teaching ";. language text shallow 
Chinese language teaching" tool theory "based. Therefore, the indicator of significance "cultural language" of learning and cognition is much larger than the "Tools language", the so-called "cultural language" is to convey the "deep language" feature culturally meaningful; relative terms, "Tools Language" is "shallow language" feature only serve cognitive meaning, "language and culture are symbiotic, interdependent, the two are closely related; language is not only an important and prominent cultural component, and also a form of cultural expression; the same time, it is the product of culture "(Chen Guanglei, 1992) Therefore, under the interdependent relationship between language and cultural interdependent and inseparable, and demonstrate the importance of cultural language than the language in Chinese language teaching tool, and" any form of language, can load a certain culture, language form only given a certain culture, is meaningful. "(Lu Jian Ji, 1990) This is an important issue of Chinese language teaching. Although the early Chinese language teaching, some scholars argued that the language is better than the importance of culture in the relationship, "'" Language Teaching "and" culture teaching "is:" Language Teaching "mainly" cultural education "as the second;" language Teaching "is the goal," cultural education "but only one mean. "(Alex Chen, 1995) as follows:

To integrate into the culture teaching in language teaching, we must first grasp the principles of a good combination of both, and that is: You must follow the language teaching, cultural teaching times; culture teaching must for language teaching services; language teaching at the same time, organic , the proper, principled destination join cultural teaching content. (Lu Jian Ji, 1990)

But as times change, the relationship between multiculturalism conduct, language and culture, and with is quite different. Bilingual teaching, between language and culture of both the "language as a mirror", "culture is like" a "mirror image"; and "culture as far as," "language processing" to seek language justifications "justifications relations", this language and culture are both in "body culture", "language with" significant relationship "Only when we put the language defined as a symbol that can be used to communication, and can be used for cross-cultural communication tool, cultural factors can become one of the indispensable elements of language and pronunciation, grammar, vocabulary, equally important status "(Lin Guoli, 1996.1) However," shaped the culture "from" shape under the language "be reflected;." specific language "from" abstract culture "reproduction," in short, the language relatively speaking, the so-called culture is relatively not fathom the language part, and pronunciation, grammar is the language of the comparison can be elusive part, or that language is there are traces rectifiable, and culture is no trace rectifiable. "(Zhou Zhiping, 2005) Therefore, bilingual education, only the integration of cultural factors before they cross the cultural divide, crossing ethnic language restrictions, alien shrink multi-cultural distance, cultural barriers and break through the barriers that language reproduce cultural soul language. Therefore, the "language and culture are closely related." Bilingual teaching both in a "relationship of body" is for the chain, is not required to off also.

For Chinese language teaching practices in terms of language teaching and culture teaching materials can be divided into two kinds, "to cultural projects as the key link, all around cultural projects; mainly in the form of language, and cultural projects closely." (Lu Jian Ji, 1990) language teaching and culture teaching methods can be divided into three types, "the text itself is directly introduced cultural projects; cultural projects reflect the needs of the text description of the scene indicated by;. text to explain cultural projects by the comment" (Lai Kim set, 1992) in Chinese language teaching language, culture is as subtle mastery "direct sense of teaching," so that students feel directly the core idea of justice Han Chinese culture. Therefore, for Chinese language teaching compilation methods, as described below:

On the basis of language teaching stage, combined with the method of language, culture teaching mainly two: one in the preparation of the course will pay attention to the cultural content into the text, so that learners learn the language but also to education and cultural knowledge. And more importantly, a language teacher is found to be good at any time with culture-related content in all language texts. (Alex Chen, 1995)

In addition, the need for bilingual education in depth focus on the ideological level, which was the backbone of the essence of Chinese culture lies. And by way of multiculturalism polygonal method and multi-line development, lively and vivid to guide learners into the Chinese language in the world of the spiritual level. Because "in the process of learning a second language learner's attitude, emotional, cultural background and values are important factors that affect learning." (LI Yu-fen, 2005) so the "cause motive" is successful for Chinese language teaching "The first a factor "; Naturally, plenty of motivation, will start learners' learning autonomy," and "active participation", "the use of learner corpus choice real autonomy and participation, then the language learning the speaking and writing and cultural factors as the most complete play. "(Ye Deming, 1994.12) that is, for Chinese language teaching to be by listening, speaking, reading and writing of" the four corners of learning "process, to deepen understanding the cultural level.

\section{Multiculturalism}

Chinese language addressed before a "multicultural" education, it is bound to understand the subtle relationship between language and culture, there are many scholars discussed their relationship at all sure its inseparable "closely related" and "closely tied to nature." "because culture is the base language, no culture, language would cease to exist; no language, culture will not be stored and spread" (Ye Deming, 1994.12) so, Chinese language teaching "language" and "culture" can be described as for two important pillars of the 
Chinese language backbone architecture, its closely constituent elements both as described below:

Each nation has its own language and cultural characteristics, language and is the manifestation of national culture, is the national carrier of culture. Different cultures bring different ethnic languages, which not only generates a special semantic components of language, but the language word formation patterns also have an important impact. (Wang Yongbing, 1995)

Cultural Differences in China in recent years, the question of language teaching is to explore one of the focus, "In the eighties there is cross-cultural study of cultural differences, leading to language mistakes, this happens in cultural differences is particularly evident between the Chinese and West. Foreign language Since then, a new teaching and research focus. "(Yu Jun-ming, 1995) following the bilingual learning" cross-language perspective, "Research angle is important to explore cross-cultural perspective," the "," Chinese language culture are inseparable, Meanwhile the Chinese culture and Western culture there are differences, each have their own characteristics. "(Ye Deming, 1994.12) although the study" language and culture still in its infancy, to discuss the characteristics of Chinese national culture more articles discuss the Han ethnic culture less affected by Chinese learning articles. "(Hu Mingyang, 1994) Chinese culture for Chinese language teaching broad and deep level of influence, which was not whether the actual phenomenon of home teaching scene. Therefore, the "cross-cultural between the Chinese and West." in Chinese language teaching, is construction of one of the priorities multicultural trends

Chinese people have always dominated Confucianism, Taoism and Buddhism plus inclusive thinking, "In contrast, Western countries are technology, business, power, competition, individualism as the main social and cultural structure, thus making the West Asians have different cultural identity. "(Huang Miriam, 1996) Therefore, its inheritance out the cultural heritage of the different characteristics of the East and Western culture.

Edified with the establishment of Chinese language teaching is to deepen the key essence of the "cultural knowledge". In addition to listening to promote Chinese language teaching of the language, speaking, reading and writing, "the four corners of learning", "promote learner-depth understanding of the potential for the Chinese culture, and skilled use of language to explore the underlying causes of the problem, the formation of thinking, and thus enrich their cultural conservation and improve listening, speaking, reading and writing ability in four language abilities."(Lin Yihua, 2005) also may further enhance the learners' motivation to learn Chinese language, culture and virtue, and moral qualities, this Chinese language learning has become elevated to a" life of Chinese , "and" soul Chinese "deep infection of everyday life for the learner, and then realized where the wisdom of Chinese culture, and moral education of Confucian thinking; then deepen to the core value of" Chinese culture knowledge ", and" whether it is the Confucian culture circle, or Chinese cultural circle, reflects a value connotation beyond national borders "(Qiu Jin, 1995) Therefore, related topics and teaching methods" cultural knowledge "is becoming one of the core subjects of Chinese language teaching:

Language is the carrier of culture, but also reflects a national customs, thoughts and feelings as well as a mirror of the national character. Chinese, idioms, proverbs, twisters is my Chinese culture for thousands of crystals, wisdom and life experience. Language and culture are closely related, it is flesh and blood relationship can be said to be self-evident. Cultural differences and language ...... cultural connotations are the focus of teaching. (Yu Jun-ming, 1995)

For the category of "cultural knowledge" is for the very rich of "multiple intelligences crystal", areas covered by broad and deep long. Whether it's history, literature, habits; or knowledge, belief, art, morals, law, custom, ability, and habits ...... etc. category, jointly constructed by the general public are all life wisdom, knowledge and life, as British culture anthropologist, Edward Tai-Yao under the definition of "primitive cultures", a book, "Culture is a complex body, including his knowledge, belief, art, morals, law, custom and the rest of the community learned abilities and habits. "(Lin Jicheng, 1990) so, through the guidance of Chinese culture, and Chinese and Western cultures of East and West, and even multicultural" comparative pedagogy "will enhance the effectiveness of the implementation of Chinese language teaching.

The so-called "multi-cultural pedagogy", in addition to Chinese and Western cultures, and compare multicultural teaching, including teaching pipes, and the way of "diversity pipeline learning," and carry forward the Chinese culture for thousands of years of spiritual wealth "diverse perspectives learning. "In addition, the scope of Chinese culture in addition to classical culture, including the unique cultural connotation of modern culture, diverse ethnic groups in Taiwan and in the field of culture, even minorities. Because minority culture in mainstream culture, Taiwanese culture in Chinese culture, Chinese culture is to the alien culture, oriental culture to Western culture, there is a value in between multicultural global all have a unique and irreplaceable "cultural location ", as follows:

On cultural identity, the ethnic minority immigrants feel the difference between themselves and the mainstream society, often specifically chosen as a symbol of some cultural traits of ethnic identity, language is a relatively distinct cultural characteristics can be used to distinguish, the language as an important factor in the cultural identity of many examples in history. (Yangcong Rong, 1995)

So, in the above "multicultural Aspects' arguments in shows, positioning multiculturalism in Chinese language teaching is a decisive value. Under the "multi-cultural knowledge" promotion, bound for Chinese language learners can produce "a pluralistic perspective of learning" to construct "multiple intelligence development" of "multi-core mode of thinking" to mastery learning materials known and heard. 


\section{The Chinese Language Integration Courses}

Teaching practices do not change easily. (Corey Webel, Douglas Platt ,2014) For planning and construction, "Chinese language integration courses" in the teaching tentacles extend to a wide range of education levels, and a variety of teaching methods oriented; and teaching multicultural and diverse characteristics of the teaching material, in order to develop a new culture of cognition "pluralistic thinking", and a full range of perspectives "polygonal learning." So, will deepen to "multiple intelligences" of "all-round cultural program" because cultural courses symbolic indicator of significance is the Chinese language teaching "comprehensive integrated curriculum" trend analysis. Areas it covers are infinitely broad and deep, and the future development of the infinite, covered the "cultural language", "grammar culture", "cultural attitude", "cultural thinking", "cultural connotations", "communication culture", "cross-border culture "," comparing culture "...... so integrated curriculum, in-depth social, economic, educational, political, literary, ethnicity, belief, art, morals, law, custom, ability, history, and lifestyle ...... etc. related areas, "Chinese language knowledge society", as shown below.

First, because the language of the "cultural factors" culvert where righteousness is at the core, so how language reflects culture depth, and breadth is very important for curriculum planning and therefore the so-called "cultural language" courses will be targeted language cultural context show, that is unique and relevant national cultural characteristics, such as psychological status, values, lifestyles, ways of thinking, moral standards, is non-standard, customs, aesthetics ...... and so on cultural factors, because "vocabulary reflect the social and cultural arteries. change language and cultural variations exist "total change." Social and cultural changes are manifested in natural language. "(Huang Guiying, 2006) so the" cultural language "courses in Chinese language teaching, curriculum planning is having inevitability. The findings suggest that cultural differences in classroom management play a significant role in affecting Chinese language teachers' classroom instruction and must be addressed in Chinese language teachers' preparation programs as well as their continued professional development in the U.S. and similar contexts. (Wenying Zhou*, Guofang Li*,2014)

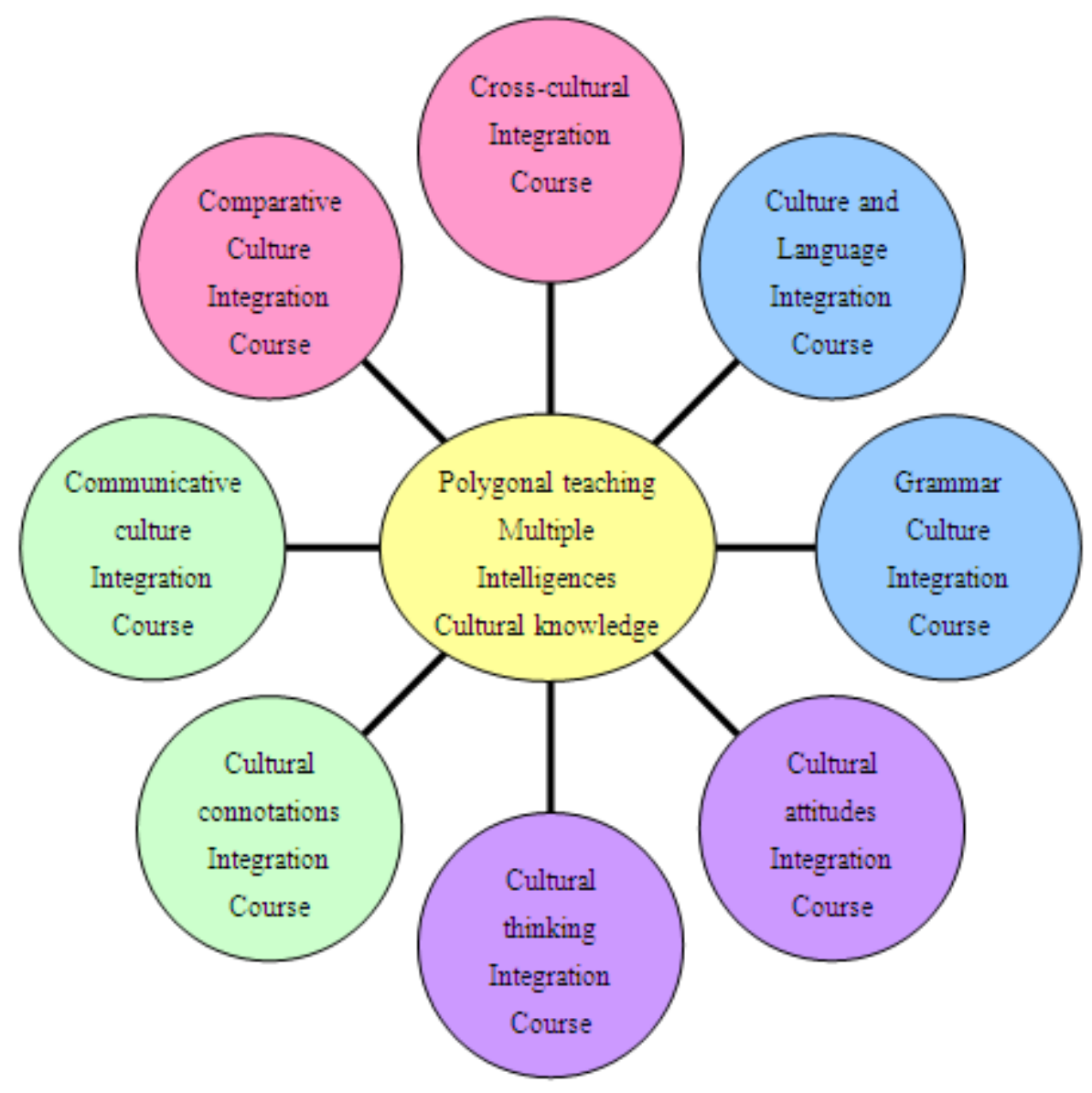

Figure 1. Chinese Teaching model 
Then, the language in the above discussion is for the "Tools Language", so has the need for learning, as teaching grammar will assist the deepening of Chinese language cognitive level, so many grammar, grammar curriculum and planning is of importance, illustration on the implementation of teaching practices, such as "in the United States, Chinese schools in addition to teaching Chinese, but also the dissemination of Chinese culture, and even the establishment of cultural classes, in fact, the causes of cultural classes not only to introduce Chinese culture, but also for many has completed a formal Chinese grammar course. "(season Town, 1994.12.27-30) such curriculum planning called" grammar culture "curriculum planning, which courses will eventually be able to learn the syntax of alien cultures, and different cultures presented national character.

Chinese language teaching face "cross - ethnic culture" environment for alien cultural connotations across, and the experience is as important issues. "The teacher through text sources, transformation, word meaning, the text content and supplementary teaching materials, etc., virtually injected introduce Chinese culture, the monasteries of the group within the outer yellow white Chinese descent add connotation of Chinese culture. "(Huang Guiying, 2006) so the" cultural connotations "curriculum planning is very important," Chinese language essence of cultural values and awareness, Writing is the expression of ideas, which is the meaning of culture. "(season Town, 1994.12.27-30) Thus, in the field of cultural knowledge and profound Chinese culture, and in a wide range of acquisition learner" after the basics of the language and cultural background ", for the" cultural knowledge "in" cultural values "deep roots, and" cultural awareness "deepening, will be an important goal of teaching" cultural connotations "courses.

In addition, after the Chinese language learners "cultural connotations" of course the foundation, and then construct a so-called "culture of thinking" ideas, "in order to reflect these values in order heritage of outstanding classical civilization, to the country where we are more rapid development, so that more people (especially the younger generation) through characters understand the essence of Confucianism and cultural connotations, is our noble duty. "(Qiu Jin, 1995) Therefore, planning a" cultural thinking "course will enable the Chinese language Teaching can only really make the cultural essence of Chinese language learners are "internalized" in the ideological level. Later, planning a "cultural attitude" curriculum and learner cognition of Chinese culture, and then the show "cultural attitude" is for the practical experience "outside now" because learners face "cultural multi-faceted" and diversity different place to learn the background, all will affect the "learning value" Chinese language teaching learners produced "practicality", and the "prominence" of "individual differences."

The most important cultural curriculum planning is to "cross-cultural" and "Comparative Culture" course, which was for Chinese language teaching and learning has considerable influence, and benefit, "a different culture, language meaning, sentence meaning there different definitions and realize, so Chinese teachers should pay attention to cultural differences and avoid the wrong perception and unnecessary conflict. ...... different times, cultural differences also generated considerable. "(Zhu Jinghua, 2006) Therefore "Pragmatic Failure" how to avoid differences caused by cultural backgrounds, and even so communicative conflict, and cultural misunderstanding, namely "cross-cultural" and "comparative culture" should face courses, and teaching the subject addressed, and target, "because cross-cultural communication is communication between people from different cultures Chinese, the middle of the process involved in ideas, attitudes, psychological and values, among other factors, rather complex, showing awareness of intercultural communication and teaching are closely related." (Huang Guiying, 2006) how to deal with "cross-cultural curriculum" covered "communicative perception", "cultural attitude", "psychological adjustment" cross-cultural "value of thinking", and with the course of study comparative culture, will be the main teaching objectives.

Finally, the effectiveness of learning Chinese language teaching in the concrete implementation in everyday life, is bound to show relationships in the face of "communicative culture", so the plan "Cultural Communication" course will be an important way to test the effectiveness of Chinese language teaching, and one of the pipeline, "in terms of communication and cultural expression system is the most prominent. ...... communicative culture in pragmatics performance was also very prominent." (Zhang Hongyu, 1995) Therefore, Chinese language teaching process, the need to focus on learning "Intercultural Communication" cultural attitudes, and ways. Because of the importance of cultural factors, and the complexity of cultural knowledge, making the so-called "body language" has become an important way to communicate with the link, "body language has a national character, and thus cross-cultural communication is misleading; nonverbal behavior resulting pragmatic vagueness may have different interpretations of the meaning, understanding non-verbal behavior will help smooth communication. "(Zhang Chunhui, 2002) Therefore, the ultimate goal of teaching Chinese language, namely for learners' cultural differences cognitive "leap" interpersonal communication of proficient skills to deal with things"in capability", the depth of the" cultural knowledge "of the technology, the concrete implementation of the" communicative competence "as the main topic.

\section{Conclusions}

For the definition of cross-border Chinese language teaching language and culture, and theoretical thinking, mainly in the "language school" scholars affirmed the core values of the language, the core connotation of "cultural faction" scholars advocate culture, and "centrist" scholars the emphasis on both individual and Nature. In this paper, for bilingual teaching Chinese language teaching, multicultural 
theory, and Chinese language curriculum integration, and planning, summarized, analyzed, and specific recommendations. I believe that the "culture" will be constructed elements of Chinese language teaching, "the power of culture to change the language can be large, so that language and cultural services." (Yeshu Han, 2004) In addition, the learner the best way to learn is to make infiltration in the Chinese language culture, as subtle, monasteries is for the best, "internalized" approach. Later, "outside now," the implementation of practical function in everyday life among "The aim of foreign language teaching is not only a professor of language knowledge, but to train learners in sociolinguistics and cultural communicative competence." (Jin Jie, Yang Yi , 2002) Therefore, "Chinese language integration courses" will be a full range of learning perspective, with a wide range of learning levels, construct the important thinking "cross-cultural equality", and "'" culture "is basically no ranking points, only usage the other, ...... therefore respect the different cultures and learn to appreciate the beauty of culture in foreign Chinese teaching or second language teaching, so that is a necessary task. "(Chenbei Ting, Ma Yufeng, 2006) As the author of the contemporary Neo-Confucian culture advocate for interracial cross upcoming" benevolence "interpreted as" for different ethnic groups, the culture itself respect and compassion, "ahead of the game, it is considered" Cultural Language, "' Grammar Culture "," Cultural Attitude "," Cultural Thinking "," Cultural Connotations "," Communication Culture "," Cross-Cultural "," Comparative Culture, "and then from" Cross-Cultural Knowledge to construct thinking ", and deepen to "Cross-Cultural Identity" cultural attitudes, will become the core of the teaching objectives of "Chinese language integration courses". The caring teaching model created an esthetic situation and experiential learning style for teaching caring that was integrated within the curricula.(Yujie Guo, Jie Shen , Xuchun Ye, Huali Chen, Anli Jiang, 2012)

\section{REFERENCES}

[1] Hu Mingyang (1994). "Fourth International Chinese Language Teaching Symposium Proceedings (order)."

[2] KWOK Kam rafter (1993). "Chinese and Chinese traditional culture." Beijing: Renmin University of China Press.

[3] Chen Yuan (1985). "Social Linguistics." Taipei: Academia Press, page 6.

[4] Sun Yi Xin (2002.9). "Mind Mapping • Basics - diverse knowledge management system." BanQiao: Yale International Culture Publishing House.

[5] Sun Yi Xin (2002.10). "Mind Mapping A Advanced articles diverse knowledge management system." BanQiao: Yale International Culture Publishing House.

[6] Lai Kim set (1992). "Language and Culture." Taipei: Lianhe Zaobao, p 25-26.9.
[7] Edward • Edward said (1999) (Edward W.Said), "Orientalism." Taipei: Li Xu Press.

[8] Edward - Tellabs (1992) (Edward Taylor) (1871). "Primitive Culture." Shanghai: Shanghai Literature and Art Publishing House.

[9] Yu Jun-ming (1995). < How to cultural factors dissolved Vocabulary Teaching>. "World Chinese Language Teaching Symposium fifth (group teaching application - on the books)." Taipei: Chinese Education Association, page 151.

[10] Bu Ai Ying (1995). <Cultural Comparison between Chinese Teaching interactive $>$. "World Chinese Language Teaching Symposium fifth (group teaching application - on the books)." Taipei: Chinese Education Association, page 87.

[11] Wangyong Bing (1995). $<$ Chinese language teaching cultural factors in teaching $>$. "World Chinese Language Teaching Symposium fifth (group teaching application * on the books)." Taipei: Chinese Education Association, page 105.

[12] Wang Xiaojun (2005). <See Business Chinese learners' communicative needs of teaching practice>. "Retrospect and Prospect of Chinese teaching theory and practice," Zhenqing, Chen Yafen, Liang Xinxin editor. Taipei: Normal College issue, pages 386-387.

[13] Qiu Jin. <Chinese culture and modernization in Southeast Asia young service>. "Southeast Asian Chinese teaching seminars." Spoke at the meeting. "World Chinese Language Teaching Symposium fifth (group teaching application • next book)." Taipei: Chinese Education Association, page 115 .

[14] Lin Xu Xing (1988.12). $<$ Chinese teaching and traditional values of the culture>. "Preparatory School and Middle School Chinese Language Teaching Seminar to discuss the report of the actual words."

[15] Lin Yihua (2005). <Chinese language and cultural teaching design - gender and cultural composition teaching theme>. "2005 Taiwan and China Language Education Symposium." Chungli: Central University Language Centre, page 141.

[16] Lin Guoli (1996.1). <Qualitative and quantitative problems locating foreign language teaching and cultural factors when meeting>. "Language Teaching and Research." Beijing: Beijing Language and Culture University.

[17] LI Yu-fen (2005). <Oral report function: Cornell University Chinese eagles class experience>. "Retrospect and Prospect of Chinese teaching theory and practice," Zhenqing, Chen Yafen, Liang Xinxin editor. Taipei: Normal College issue, page 267.

[18] Lee Kuan Yew (1990). <World teaching seminars Chinese opening address $>$. "World Chinese Teaching Proceedings." Pages 5-6.

[19] Sean Covey (Sean Covey). <Develop seven kinds of high-performance habit>. "Future about - the younger you will face six key decisions." Taipei: Commonwealth Magazine Press.

[20] Jin Jie, Yang Yi (2002). <Nonverbal Communication and Foreign Language Teaching $>$. "Zhuzhou Institute of Technology", Volume XVI. Zhuzhou: Zhuzhou Institute of Technology, pages 68-69.

[21] Chiu Yin Yu (2004). <Nonverbal Communication and Chinese Language Teaching>. "2004 Taiwan and China 
Language Education Symposium." Ilan: Buddha College of Humanities, page 120.

[22] Quarter Town (1994.12.27-30). <American Chinese School Culture class presentation>. "The Fourth World Chinese Language Teaching Symposium (Teaching report group)." Taipei: Chinese Education Association, page 63.

[23] Zhou Ping (1994.12.27-30). < Overseas Chinese learners of culture shock and adaptation>. "The Fourth World Chinese Language Teaching Symposium (Teaching report group)." Taipei: Chinese Education Association, page 173.

[24] Zhou Zhiping (2005). <Fluently and accurately: the past two decades of American foreign language teaching council>. "Retrospect and Prospect of Chinese teaching theory and practice," Zhenqing, Chen Yafen, Liang Xinxin editor. Taipei: Normal College issue, page 10.

[25] Lvbi Song. <Introduction to Foreign Language Teaching> (handouts). "State Board of Education as a Foreign Language Teacher Credentials Committee Office" (internal data). "World Chinese Language Teaching Symposium fifth (group teaching application . next book)." Taipei: Chinese Education Association, page 115.

[26] Lii (1980). <Language as a social phenomenon>. "Reading", the first four. Beijing: reading magazines Press.

[27] Zhu jingHua (2006). <Order theory>. "Chinese language teaching takes practice theory." Taipei: History and Philosophy Press.

[28] Xu Zhen (1995). <Talk about the basic language courses in language teaching and culture teaching problem $>$. "World Chinese Language Teaching Symposium fifth (group teaching application - on the books)." Taipei: Chinese Education Association.

[29] Chen Guanglei (1992). <Language teaching and cultural import>. "Language Teaching and Research" Section 3. Beijing: Beijing Language and Culture University, page 20

[30] Chenbei Ting, Mayu Feng (2006). <Same in different • different but have the same - On the Lunar New Year in Chinese and Thai culture and its related words $>$. "2006 Taiwan and China Language Education Symposium." Kaohsiung: Normal Chinese Language Teaching Institute, page 372 .

[31] Koh Hock Kiat (1995). < Relationship between Chinese and Chinese culture knowledge - Singapore Junior College Relations learner language and culture research>. "World Chinese Language Teaching Symposium fifth (group teaching application - on the books)." Taipei: Chinese Education Association, page 111.

[32] Pengzeng An (1997). $<$ On the language in the language of intercultural communication failures>. "Learning Chinese" fifth. Jilin: Yanbian University of Chinese learning Editorial Department, pages 40-41.

[33] Huang Guiying (2006). < Glimpse awareness of intercultural communication from Chinese textbooks>. "Operations Strategy and International Symposium on Teaching Chinese institutions Proceedings twenty-first century." Taipei: International Symposium on the fiftieth anniversary of the Mandarin Training Center of National Taiwan Normal University, page 181 .

[34] Huang Miriam (1996). < About Chinese people's social habits from the correlation between language and culture>. "The first session of the New Zealand Chinese Language Teaching Symposium." Taipei: National Taiwan Normal University Chinese Department, page 251.

[35] Following Wan Bi, Zhang Dexin (1994). $<$ Foreign language teaching and cultural research questions>. "Applied Linguistics", page 2. Beijing: National Language Committee language community newspapers, page 40 .

[36] Zhang accounting for a (1996.1). $<$ Foreign language teaching profession two shares cultural Wind $>$. "China's foreign language teaching Society to commemorate the tenth anniversary of selected papers." Beijing: Beijing Language Institute Press.

[37] Zhang Hongyu (1995). $<$ Write some questions that occur to materials for the weekend Chinese schools>. "World Chinese Language Teaching Symposium fifth (group teaching application · next book)." Taipei: Chinese Education Association, page 113.

[38] Zhang Chunhui (2002). <Main features of Body Language in Chinese teaching the importance>. "Hunan Agricultural University", Volume III, Phase IV. Hunan: Hunan Agricultural University, pp 69-71.

[39] Linji Cheng (1990). <Language and Culture comprehensive theory>. "Language and Culture." Gu Jiazu editor. Shanghai: Shanghai Foreign Language Education Press, page 3.

[40] Yangcong Rong (1995). <Cultural Identity and Cultural Capital: New development of language problems Indonesia and China $>$. "World Chinese Language Teaching Symposium fifth (group teaching application - on the books)." Taipei: Chinese Education Association, page 257.

[41] Ye Deming (1996). <Language trend of social changes Taipei Mandarin>. "The first session of the New Zealand Chinese Language Teaching Symposium." Taipei: National Taiwan Normal University Chinese Department, page 63.

[42] Ye Deming (1994.12). $<$ Chinese Language Teaching Second Language Advisory justice>. "Chinese world", the first 74. Taipei: Chinese Education Association.

[43] Yeshu Han (2004). <Trial comparing discuss their relationship between language and culture between China and South Korea from greeting>. "2004 Taiwan and China Language Education Symposium." Ilan: Buddha College of Humanities, page 317.

[44] Zhao Zhichao (2005). <Observations and Reflections on Chinese Teaching $>$. "Retrospect and Prospect of Chinese teaching theory and practice," Zhenqing, Chen Yafen, Liang Xinxin editor. Taipei: Normal College issue, page 7.

[45] Lu Jian Ji (1990). <Foreign Language Teaching Basic principles of dealing with cultural factors and practices $>$. "Language Teaching and Research", the first one. Beijing: Beijing Language and Culture University, pp 43-45.

[46] Yujie Guo, Jie Shen, Xuchun Ye, Huali Chen, Anli Jiang (2014) . < The design and testing of a caring teaching model based on the theoretical framework of caring in the Chinese Context: A mixed-method study $>$." Nurse Education Today 33 ",School of Nursing, Second Military Medical University, Shanghai 200433, PR China pp 912-918.

[47] Wenying Zhou, Guofang Li (2014) . <Chinese language teachers' expectations and perceptions of American students' 
behavior: Exploring the nexus of cultural differences and classroom management $>$."System 49 "Michigan State University, USA pp 17-27.

[48] Corey Webel, Douglas Platt (2014), < The role of professional obligations in working to change one's teaching practices >." Teaching and Teacher Education 47 " a Department of Mathematical Sciences, Montclair State University, 1 Normal Ave, Montclair, NJ, 07043, USA b Department of Learning, Teaching, and Curriculum, University of Missouri, 121C Townsend Hall, Columbia, MO, 65211, USA pp204-217 